\title{
Mejorando la Respuesta a la Diversidad en el Aula a través del Estudio de Clases en Escuelas Chilenas
}

\section{Improving Response to Diversity in the Classroom through Lesson Study in Chilean Schools}

\author{
Cynthia Duk * \\ Francisco Hernández-Ojeda \\ Universidad Central de Chile, Chile
}

\begin{abstract}
Esta investigación busca comprender los significados y sentidos que le atribuyen los docentes al Estudio de Clase (Lesson Study) como estrategia de desarrollo profesional para la mejora de la respuesta a la diversidad en el aula. Desde en un enfoque descriptivo interpretativo propio de la investigación cualitativa y un diseño de estudio de caso, los datos se recogieron a través de entrevistas semiestructuradas en una muestra intencionada de docentes que se desempeñan en dos escuelas públicas chilenas. Además, se realizó análisis de documentos elaborados por los participantes durante el proceso de EC. Los hallazgos revelan que el Estudio de Clase es una estrategia con gran potencial para promover la reflexión y la mejora de las prácticas educativas desde un enfoque inclusivo, fortalecer la colaboración y aprendizaje mutuo entre docentes, desarrollar nuevas estrategias para responder a la diversidad de estudiantes. Asimismo, la investigación permitió identificar algunos factores críticos necesarios de tener en cuenta para el éxito de futuras aplicaciones de esta metodología en contextos formativos. Finalmente, este estudio permite reafirmar la relevancia del Estudio de Clase como propuesta innovadora y efectiva en el ámbito de la formación continua para promover cambios y avanzar hacia prácticas más inclusivas en el aula.
\end{abstract}

Descriptores: Diversidad; Educación integradora; Prácticas pedagógicas; Estudio de clase; Formación continua.

This research aims to understand the meanings that teachers attribute to Lesson Study as a professional development strategy to improve de response to diversity in the classroom. From a descriptive interpretative approach of qualitative research and a case study design, the data was collected through semi-structured interviews in an intentional sample of teachers working in two Chilean public schools. In addition, analysis of documents prepared by the participants was performed. The findings reveal that Lesson Study is a strategy with a great potential to promote reflection and improvement of educational practices from an inclusive approach, to strengthen collaboration and learning among teachers, to develop new strategies to respond to diversity. The research also identified some critical factors necessary to take into account for the success of future applications of this methodology in training contexts. Finally, this study allows us to reaffirm the relevance of Lesson Study as an innovative and effective proposal in the field of continuous training, in order to promote changes and move towards inclusive practices in the classroom.

Keywords: Diversity; Inclusive education; Pedagogical practices; Lesson study; Teacher education.

*Contacto: cduk@ucentral.cl

ISSN: 2254-3139

www.rinace.net/riejs/

revistas.uam.es/riejs
Recibido: $\quad 15$ de octubre 2019

$1^{\text {a }}$ Evaluación: 13 de diciembre 2019

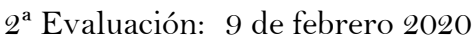

Aceptado: 2 de marzo 2020 


\section{Introducción}

No cabe duda que uno de los mayores desafíos que enfrentan los sistemas educativos de América Latina, al igual que en Chile, es cómo afrontar la composición crecientemente más diversa de la población que asiste a las escuelas, como consecuencia de los importantes avances en materia de cobertura y universalización de la educación en los niveles obligatorios alcanzados en décadas pasadas; el reconocimiento de la educación como derecho social que debe ser garantizado por el estado, y la inclusión educativa como un componente esencial del ejercicio de este derecho y una condición fundamental para la construcción de sociedades más cohesionadas, equitativas y democráticas (Ainscow et al., 2013; Blanco, 2014; Echeita y Ainscow, 2011)

En este contexto, cabe mencionar la emergencia de lo que podríamos llamar "nuevas diversidades" que interpelan a la escuela y al sistema educativo en su conjunto. El aumento del fenómeno de la migración y su impacto en la educación, o el reconocimiento de las identidades de género y diversidad sexual invisibilizadas hasta no hace mucho, junto con la creciente integración de estudiantes con discapacidad al aula común, son ejemplos que ponen de relieve la magnitud y complejidad del desafío que supone satisfacer las necesidades de aprendizaje y participación de todos los estudiantes más allá de sus diferencias (socioeconómicas, culturales, lingüísticas, capacidades, origen étnico o género).

Esta realidad ha puesto en el centro del debate, la imperiosa necesidad de superar las prácticas homogeneizadoras de la enseñanza que persisten hasta nuestros días, que no dan cuenta de la realidad cada vez más heterogénea de las escuelas y sus aulas, ni responde al llamado ético que tiene la escuela de avanzar en la dirección de una mayor inclusión educativa y social, evitando que las desigualdades sociales se conviertan en desigualdades educativas (Blanco, 2014). Frente a este escenario, se hace necesario generar condiciones que favorezcan una gestión curricular inclusiva y estrategias de enseñanza más diversificadas y flexibles (Cisternas y Lobos, 2019; Duk, 2014), que aseguren la participación y aprendizaje de los y las estudiantes como garantía del derecho que a todos les asiste de recibir una educación equitativa y de calidad.

A la fecha existe abundante evidencia que permite afirmar que una de las barreras más importantes para avanzar hacia prácticas más inclusivas, es la percepción de los docentes en todos los niveles de enseñanza, que no se sienten suficientemente preparados ni capacitados para responder de manera efectiva a la amplia diversidad de características y necesidades educativas que conforman el aula (García, Herrera y Vanegas, 2018; OECD, 2014; Zárate-Rueda, Díaz-Orozco y Ortiz-Guzmán, 2017).

En Chile como en la mayoría de los países latinoamericanos, las políticas de formación continua y desarrollo profesional en materia de educación inclusiva han sido insuficientes y en general no han logrado impactar de manera significativa las actitudes y prácticas habituales de los docentes, fuertemente arraigadas como consecuencia de los modelos de formación inicial recibidos y su posterior consolidación en el desempeño docente. Algunos de los factores que podrían explicarlo dicen relación con los siguientes aspectos (Duk, 2014): a) una débil conexión de los cursos de actualización con las problemáticas específicas de la enseñanza y el aprendizaje que tienen lugar en el aula; b) falta de apropiación de enfoques y estrategias pertinentes para el abordaje de la diversidad por parte de los formadores; c) la escasa oferta de modalidades de formación con base en la escuela y en las necesidades compartidas de sus equipos docentes y directivos; d) una 
insuficiente consideración de las concepciones previas y creencias de los profesores respecto de las diferencias y la inclusión educativa, y e) una escasa oferta de programas que incluyan acciones de seguimiento que apoyen el desarrollo de nuevas prácticas en el contexto educativo.

A lo anterior, se agrega que la labor docente tiende a darse en forma solitaria sin que los docentes cuenten con espacios y tiempos necesarios para desarrollar la enseñanza en forma colaborativa, lo cual limita el buen aprovechamiento de las oportunidades que ofrece el aprendizaje entre pares, quedando confinado en las aulas el conocimiento y experiencia generada en la cotidianeidad de la práctica pedagógica (Ainscow, 2016; Krichesky y Murillo, 2018). Ante esta realidad, la metodología del Estudio de Clase (EC) ofrece una oportunidad de desarrollo profesional en la perspectiva de instalar procesos de mejora continua basadas en el análisis reflexivo y colaborativo sobre la práctica educativa en relación con la respuesta a la diversidad, mediante acciones curriculares articuladas entre equipos de profesores con el apoyo de formadores.

Esta investigación aprovecha la experiencia realizada en el contexto de una acción formativa con docentes de escuelas públicas de la Comuna de Peñalolén de Santiago, para indagar en los significados y sentidos que le atribuyen al EC para dar respuesta a la diversidad en el aula y, a partir de ello, aportar al desarrollo de una estrategia de formación continua con potencial para avanzar efectivamente hacia prácticas inclusivas, que proporcionen mayores oportunidades a la diversidad de estudiantes en el marco de experiencias comunes de aprendizaje.

\section{Revisión de la literatura}

El conocimiento acumulado en el campo de la formación continua y desarrollo profesional docente, ha permitido identificar algunas estrategias que han resultado exitosas para la transferencia de los aprendizajes a la práctica: la formación situada en las escuelas y basadas en las necesidades de los equipos docentes; la formación que combina teoría y práctica, generando espacios de reflexión acción a partir de la observación entre pares como recurso de aprendizaje y apoyo mutuo; la formación que contempla acompañamiento en terreno para la introducción de cambios en las practicas. En este contexto, algunos de los hallazgos del trabajo con escuelas realizado por Ainscow (2005), muestran que el cambio de las prácticas no suele suceder si no se les ofrece a los profesores la oportunidad de observar formas diferentes de llevar a cabo la docencia y de recibir observaciones sobre su propia práctica, de parte de alguien que les pueda ayudar a comprender la diferencia entre lo que están haciendo y lo que aspiran hacer o sería deseable que hicieran.

Una estrategia que se ha extendido por sus ventajas para el desarrollo de prácticas inclusivas es lo que se ha denominado como co-docencia, o co-enseñanza en el aula. Esta consiste en el trabajo conjunto de parejas de docentes que se corresponsabilizan del proceso educativo con el propósito de optimizar la enseñanza y el aprendizaje para todos los estudiantes (Rodríguez, 2014). Un proceso de apoyo colaborativo entre parejas pedagógicas, donde los docentes llevan a cabo un proceso formativo inclusivo (Cotrina, García y Caparrós, 2017) que beneficia el desarrollo de ambos y en consecuencia el aprendizaje de los estudiantes. Esta modalidad de trabajo ha tenido un gran impulso en Chile en el ámbito de la política de integración escolar de estudiantes con necesidades educativas especiales, como medida para apoyar procesos educativos inclusivos en el aula. 
Por otra parte, Chong y Kong (2012), afirman que: “...los programas de desarrollo profesional exitosos son intensivos, continuos y vinculados a la práctica, se enfocan en temáticas específicas y fomentan relaciones sólidas de trabajo colaborativo entre los docentes" (p. 263). En este sentido, reconocen el EC como un método que provee condiciones favorables para generar estructuras efectivas de aprendizaje colaborativo para desarrollar nuevas formas de enseñanza, siendo este uno de sus atributos que ha concitado mayor interés en distintas partes del mundo.

El modelo del EC como estrategia de desarrollo profesional para la mejora del proceso de enseñanza aprendizaje, surgió en Japón hace más de 100 años y se ha extendido desde los años 90 a cerca de 60 países de distintas regiones, siendo incluso utilizado como estrategia de mejoramiento escolar a gran escala en algunos casos. Esta importante expansión ha redundado en variadas interpretaciones y ajustes al modelo en función de las variables contextuales donde se ha aplicado y los objetivos que perseguido su empleo (Hadfield y Jopling, 2016; Ramos y Reyes, 2017). En esencia, esta metodología consiste en planificar, enseñar, observar y analizar clases, en grupos de estudio integrados por docentes, generando un espacio de reflexión acción, fundamental para el desarrollo pedagógico (Barboza y Zapata, 2013; Olfos, Estrella, y Morales, 2015).

En relación a lo antes señalado, Saito (2012) introduce la idea de Lesson Study for Learning Community (LSLC), destacando las posibilidades que ofrece el EC como acción sistémica de reforma escolar en los países en desarrollo, así como la importancia de que la escuela globalmente se implique desde el inicio del proceso y que la observación y reflexión compartida se focalicen en una temática delimitada, aun cuando en una primera etapa se pueda generar confusión como suele ocurrir ante cualquier innovación. A su vez, este autor destaca . la importancia de que los docentes pongan mayor atención en los estudiantes y su respuesta frente al aprendizaje, dejando en un segundo plano la tendencia a enfocarse en los contenidos y métodos de la enseñanza

Específicamente para el caso de esta investigación, hemos tomado como referente la modalidad de EC desarrollada por el equipo de investigación internacional liderado por Messiou y Ainscow del Reino Unido, cuya innovación es que sitúa en el centro del proceso la mirada en la diversidad, poniendo el foco en la respuesta y participación todos los estudiantes del grupo durante el desarrollo de la clase. Este trabajo se inició a través de un proyecto financiado por la Unión Europea involucró a investigadores de cinco universidades europeas y a ocho establecimientos de secundaria, de tres países, Portugal, España y Reino Unido (Proyecto: Respondiendo a la Diversidad Contando con las Voces de los Estudiantes, 2011-2014).

En palabra de los autores (Messiou et al., 2016) con base a la evidencia recopilada como resultado de la investigación de acción colaborativa desarrollada en los tres países antes mencionados, proponen una estrategia innovadora para ayudar a los docentes a responder positivamente a la diversidad del alumnado. La estrategia integra el EC con la voz de los estudiantes, incorporando sus puntos de vista en las distintas fases del proceso. Los autores señalan que este aspecto es el que marca la diferencia para la atención a la diversidad del alumnado, y remarcan que escuchar a los estudiantes tiene el potencial de desafiar a los docentes a ir más allá del intercambio de prácticas existentes, motivándolos a explorar nuevas alternativas para implicar a los alumnos/as de manera activa en las clases. Estos autores definen el EC para el desarrollo de prácticas inclusivas, como un 
proceso de investigación acción colaborativa que se desarrolla según los siguientes pasos (Messiou et al., 2014):

- Creación de equipos cooperativos de profesores que planifican sus clases juntos con un mismo grupo/curso. Idealmente se forman tríos, pero puede aplicarse con parejas o grupos de 4 docentes.

- Antes de planificar la clase que van a llevar a cabo, los profesores dialogan en torno a la diversidad que caracteriza al grupo de estudiantes. ¿Qué deben tener en cuenta para lograr que todos se motiven y participen de la clase? ¿Qué necesitan mejorar?

- Mientras uno de los docentes imparte clase, los demás asumen un rol de observación, prestando particular atención en la participación de los estudiantes.

- Posteriormente, los profesores se reúnen y comparten sus observaciones para mejorar su planificación. Introducen las mejoras o ajustes que estimen.

- Entonces, el siguiente profesor imparte la clase mejorada y los demás compañeros observan.

- Este proceso se repite hasta que todos los integrantes del equipo, han tenido ocasión de impartir la clase una vez.

- Las implicaciones y aprendizajes sobre la práctica se identifican al final del proceso, esto es, cuando se ha cumplido un ciclo de mejora.

En el caso particular de Chile, no existen experiencias previas que utilicen el EC con el objetivo de promover el desarrollo de prácticas inclusivas. Las referencias con que se cuenta están referidas principalmente al campo disciplinar de la matemática. Sin embargo, resultan interesantes los hallazgos encontrados por el equipo de investigadores la Universidad Católica de Valparaíso, que reafirman las ventajas que el EC presenta para el desarrollo docente y la mejora de la enseñanza, por tratarse de una metodología que basada en la colaboración promueve la reflexión acción entre docentes, a partir de la evidencia reunida durante el EC (Olfos, Estrella y Morales, 2015). La experiencia de EC analizada en esta investigación está inspirada en el proyecto de la Unión Europea mencionado y se desarrolló mediante los pasos metodológicos antes descritos (Massieu et al., 2014) con los ajustes pertinentes acordes a la realidad chilena y al contexto de escuelas básicas municipales de la Comuna de Peñalolén.

Este estudio tiene por objetivo comprender los significados y sentidos que los docentes le atribuyen al EC para la mejora de la respuesta educativa a la diversidad del aula, identificando aquellos factores que consideran facilitan o dificultan su implementación. Ello permitirá profundizar en el proceso de EC como estrategia de desarrollo profesional docente, para avanzar hacia prácticas pedagógicas más inclusivas y colaborativas que favorezcan la participación y aprendizaje de la diversidad de estudiantes , una necesidad relevante en todos los niveles del sistema escolar nacional.

\section{Método}

La presente investigación se basa en un enfoque cualitativo de tipo descriptivo interpretativo, y un diseño de estudio de caso, esto es, el estudio intensivo y profundo de uno o múltiples casos situados en un contexto específico, un grupo de docentes de 2 
escuelas municipales, en relación a un objeto de estudio, los significados y sentidos atribuidos al proceso de EC.

El campo de estudio son 40 docentes (educadoras de párvulos, profesores de educación básica y diferencial) de escuelas públicas de la Comuna de Peñalolén, que participan en procesos de EC en el centro educativo donde ejercen profesionalmente, como componente de su práctica formativa en el contexto del Diplomado en Inclusión Educativa y Diversidad, impartido por la Universidad Central de Chile entre agosto de 2017 y abril de 2018. De este grupo se seleccionó una muestra intencionada de 6 docentes integrantes de 3 equipos de EC que implementaron la experiencia en 2 escuelas de la comuna. Los criterios de selección fueron los siguientes:

- Que impartieran docencia en niveles de educación parvularia (inicial) o básica.

- Haber participado como miembro de un equipo (de 2 a 4 participantes) de EC para la respuesta a la diversidad en el aula, en el segundo semestre de 2017.

- Haber entregado los documentos y registros del proceso de EC (informe, planificación de clases, registro de observación), solicitados por el Diplomado.

- Que como equipo hubieran completado, dentro del proceso de EC, un ciclo de al menos dos clases, con su planificación, observación y retroalimentación.

- Que aceptaran participar en la presente investigación, habiendo firmado un consentimiento informado.

El entorno es de 13 escuelas públicas de educación básica que son administradas por la Corporación Municipal. La población escolar proviene en general de sectores socioculturales desfavorecidos, presenta altos índices de vulnerabilidad y gran heterogeneidad. Desde el punto de vista étnico y cultural, las escuelas tienen estudiantes de origen Mapuche y de otras nacionalidades, y todas están adscritas a un Programa Comunal de Integración Escolar. Este programa apoya los procesos de integración de alumnos que presentan necesidades educativas especiales y discapacidad, a través de disponer de educadoras diferenciales y psicopedagogas en aula que colaboran con el trabajo docente y los procesos de enseñanza y aprendizaje, atendiendo a las particularidades de dichos alumnos. En el cuadro 1 se detallan los datos de los sujetos de estudio.

Cuadro 1. Sujetos de estudio

\begin{tabular}{|c|c|c|c|c|}
\hline & \multirow[b]{2}{*}{ PARTICIPANTES } & \multirow[b]{2}{*}{ CARGO } & \multicolumn{2}{|c|}{ ANTIGÜEDAD } \\
\hline & & & Colegio & $\begin{array}{c}\text { Ejercicio } \\
\text { profesional }\end{array}$ \\
\hline \multirow[b]{2}{*}{$\begin{array}{l}\text { Escuela } 1 \\
\text { Equipo } 1\end{array}$} & Profesora Ed. Básica & Docente $4^{\circ}$ Básico & 4 & 14 \\
\hline & Ed. Diferencial & $\begin{array}{l}\text { Profesional Apoyo } 1^{\circ} \\
\text { Ciclo Básico }\end{array}$ & 20 & 22 \\
\hline \multirow{2}{*}{$\begin{array}{l}\text { Escuela } 2 \\
\text { Equipo } 2\end{array}$} & Profesora Ed. Básica & Docente $4^{\circ}$ Básico & 5 & 6 \\
\hline & Psicopedagoga & Profesional Apoyo & 4 & 4 \\
\hline \multirow{2}{*}{$\begin{array}{l}\text { Escuela } 2 \\
\text { Equipo } 3\end{array}$} & Ed. de Párvulos & Educadora Kinder & 7 & 13 \\
\hline & Ed. Diferencial & $\begin{array}{l}\text { Profesional Apoyo } 2^{\circ} \\
\text { Ciclo Básico }\end{array}$ & 2 & 2 \\
\hline
\end{tabular}

Fuente: Elaboración propia.

Las técnicas utilizadas para la obtención de la información fueron entrevistas individuales semiestructuradas, el análisis documental de las producciones de los equipos de EC 
(informes sobre el proceso de EC, registros de planificación y observación de clases) realizados durante el Diplomado citado.

\section{Entrevistas semiestructuradas individuales}

El proceso de elaboración del temario y preguntas de este instrumento se realizó según el siguiente procedimiento:

- Definición de temas, categorías de análisis, y preguntas abiertas preliminares, acordes a la pregunta y objetivos de la investigación, así como a la bibliografía consultada.

- Ajustes del temario y sus respectivas preguntas según el análisis documental inicial de los reportes escritos de los equipos de EC estableciéndose cinco categorías principales con un total de 17 preguntas.

- Validación del instrumento mediante juicio de 3 expertos en metodologías cualitativas y educación inclusiva, en base a criterios de coherencia, relevancia, pertinencia y claridad de las preguntas

- Refinamiento final del instrumento como resultado de la validación, lo que dio lugar a un total de 14 preguntas y una mayor precisión de las categorías.

Una vez seleccionados los participantes de los equipos de EC de dos escuelas, con el consentimiento de la Dirección de Educación del Municipio y de las directoras de ambas escuelas, se invitó a las docentes seleccionadas a participar en el estudio. A estos efectos, ambas escuelas facilitaron la realización de las 6 entrevistas en sus propias dependencias, bajo condiciones adecuadas.

Cada entrevista fue realizada por los dos investigadores según una pauta prevista, en forma individual y en un espacio privado, con una duración promedio de 60 minutos. Se abordaron de manera flexible las preguntas en un clima dialógico de confianza y confidencialidad. Las entrevistas fueron grabadas y posteriormente transcritas para su análisis, bajo consentimiento informado. Al término de estas, los investigadores intercambiaron impresiones tanto respecto de la forma como de la información obtenida, considerando estas apreciaciones en las siguientes entrevistas.

\section{Análisis documental de registros producidos en el proceso de EC}

El análisis de los informes del proceso de EC, con sus registros de planificación y observación, fue utilizado en dos momentos, antes y después de realizadas las entrevistas.

Los datos recogidos en los documentos producidos en el proceso del EC por todos los participantes del Diplomado fueron inicialmente sistematizados, analizados e incorporados en la construcción de las categorías temáticas y preguntas de las entrevistas.

El análisis de la información recabada a través de las entrevistas se realizó a partir de un proceso progresivo de identificación de unidades de análisis o significados desde los discursos de los participantes y la generación de categorías relacionadas con los objetivos de la investigación. Se utilizó el MAXQDA siguiendo un análisis hermenéutico de tipo inductivo, en un proceso de refinamiento de las categorías iniciales y de levantamiento de nuevas categorías o subcategorías según similitudes o diferencias, hasta su saturación en el discurso de las participantes. Posteriormente, estos datos fueron trabajados desde una perspectiva de triangulación múltiple: con los datos de los informes/registros del proceso de EC de los 3 equipos participantes; de los investigadores; y de teoría. Ello permitió 
resguardar la rigurosidad del proceso de análisis, para después contrastar los hallazgos obtenidos con el marco teórico y los resultados de investigaciones previas. De este modo, tanto en el diseño de las intervenciones e instrumentos, como en la recogida y el análisis de datos, se resguardó los criterios de rigor científico cualitativo, esto es, credibilidad, consistencia, y confirmación.

\section{Resultados}

Los resultados del estudio se presentan en el siguiente conjunto de unidades temáticas interrelacionadas, que dan cuenta de los significados y sentidos de las participantes respecto del proceso de EC en relación a la respuesta a la diversidad en el aula, según las categorías teóricas y emergentes distinguidas en los relatos de las docentes participantes, tanto desde la textualidad de las entrevistas como de los reportes escritos elaborados por las docentes en el marco del programa del Diplomado.

Como resultado de este proceso finalmente se establecieron 6 unidades temáticas (categorías) con distinciones específicas (subcategorías), que condensan los significados de las docentes, según se especifica en el cuadro 2. En cada una de las categorías se presenta textos ilustrativos que van acompañados de las referencias de las autoras, según el formato profesión (D: docente; ED: Educadora Diferencial; EP: Educadora de Párvulos), curso y escuelas (E1 y E2), o del equipo autor si estos provienen de los documentos analizados.

Cuadro 2. Resultados en unidades temáticas, con sus significados y sentidos

\begin{tabular}{ll}
\hline EXPERIENCIA DE ESTUDIO DE & \multicolumn{1}{c}{ COMPRENSIÓN DE EC } \\
CLASE ALTAMENTE VALORADA & ALTA VALORACIÓN DEL EC \\
\hline \multirow{2}{*}{ Trabajo Colaborativo } & "Trabajo colaborativo real” \\
& Foco en la práctica pedagógica \\
& Paridad y complementariedad interdisciplinaria \\
& Reciprocidad y reconocimiento \\
& Proceso constructivo de conocimiento \\
\hline \multirow{3}{*}{ Mejora de la respuesta educativa a la } & Significados sobre diversidad \\
diversidad en el aula & Conocimiento del curso y sus estudiantes \\
& Variedad de estrategias y recursos didácticos \\
& Interacciones colaborativas en el aula \\
\hline \multirow{2}{*}{ Factores facilitadores del Estudio de } & Trabajo colaborativo \\
Clase & Actitud favorable hacia el aprendizaje y el \\
& desarrollo profesional \\
& Aporte Técnico \\
& Apoyo Institucional \\
\hline \multirow{2}{*}{ Factores obstaculizadores del Estudio de } & Falta de tiempo \\
Clase & Desconocimiento de los alumnos, de la dinámica \\
& del curso, o del nivel \\
& Acciones o conductas no colaborativas \\
\hline Estudio de Clase favorece el Desarrollo & Incidencia en la mejora de la respuesta a la \\
Profesional & diversidad \\
& Formación de profesionales reflexivos \\
& Cambios en la visión de sí mismo, personal y \\
& profesionalmente \\
\hline
\end{tabular}

Fuente: Elaboración propia.

\subsection{Experiencia de EC altamente valorada}

Este tema atañe a los significados y sentidos globales respecto de participar y vivir la experiencia del proceso de EC. Implica, por un lado, una cierta comprensión compartida 
del proceso de EC y, por otro lado, una valoración muy positiva de dicha experiencia. En términos de la comprensión, las participantes conceptualizan el EC como un proceso o estrategia de reflexión acción colaborativa orientado a ampliar las oportunidades de aprendizaje y participación de los estudiantes a través desarrollo de una práctica pedagógica atenta a la diversidad en el contexto específico del aula donde se desarrollaba, según un procedimiento de planificación, implementación-observación, y retroalimentación, repetido en un ciclo de dos a tres clases.

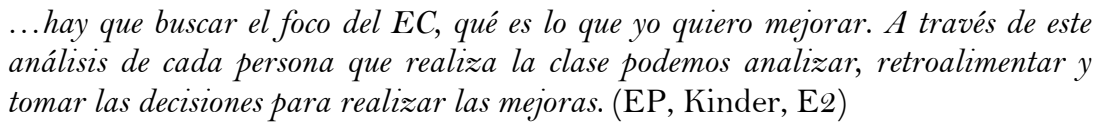

El proceso de EC adquiere, a través de las sucesivas etapas preestablecidas y guiadas, un sentido de un todo coherente, de un proceso sistemático, donde cada una de ellas aporta elementos sustantivos para la toma de decisiones conjunta respecto de cómo mejorar la práctica educativa con foco en la diversidad. A su vez, este proceso se hace más fácil y se va enriqueciendo a medida que progresa su implementación. De esta forma, la planificación se enriquece y hace más pertinente a las características de los alumnos de la clase (una planificación diversificada), la observación permite ampliar la mirada y darse cuenta de aspectos antes invisibles, la retroalimentación resulta orientadora y con sentido, en tanto ayuda a mejorar la práctica:

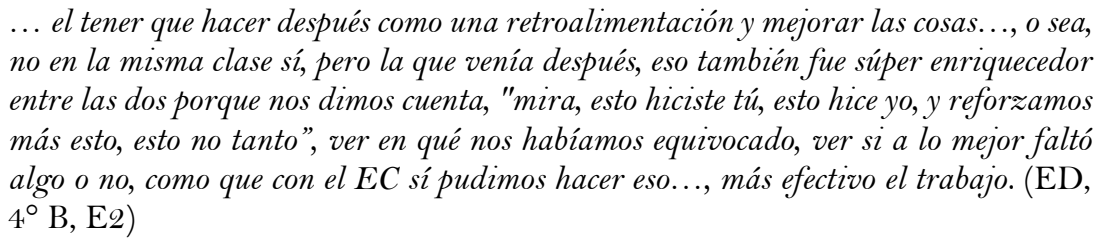

Respecto de la valoración positiva sobre la experiencia del EC, ésta se sustenta en la comprensión anterior y en una serie de apreciaciones referidas a logros respecto de las prácticas educativas, aprendizajes personales, vivencias y particularmente, a las relaciones de colaboración que, dada su altísima relevancia, se presenta separadamente como la categoría "Trabajo Colaborativo".

Destacan las posibilidades que esta metodología ofrece de observar y reflexionar sobre las propias prácticas pedagógicas y las de las otras participantes, generando nuevos conocimientos y cambios orientados a dar mejor respuesta a la diversidad, todo ello en un contexto colaborativo entre profesionales de diferentes disciplinas; la de ampliar sus habilidades de observación de los alumnos, así como su repertorio de recursos y actividades pedagógicas.

En este proceso se configuran diversos aprendizajes vinculados a cambios personales, referidos a valoraciones del otro, reafirmación de capacidades, conductas y actitudes hacia la práctica docente, que probablemente pueden incidir en el desempeño profesional.

Que yo tengo que sacar más personalidad, atreverme a hacer cosas nuevas, atreverme a participar más dentro de la sala, atreverme a acércame más a los chiquillos y llevar estrategias nuevas para que puedan aprender. De primera yo era un "pollo", y esto me ha servido para sacar "personalidad" con los chiquillos. (ED, Kinder, E2)

Al triangular los hallazgos anteriores con el análisis de contenido de los reportes escritos, en general se observa coherencia entre estas dos fuentes. Las coincidencias remiten tanto a la comprensión como a la apreciación positiva de la experiencia. Por ejemplo, algunos de estos aspectos son referidos en una de las conclusiones del informe del Equipo $\mathrm{N}^{\circ}$ 2: 
A partir de esta experiencia, nos proponemos en un futuro, continuar con la motivación al inicio de la clase, que da el punta pie para lograr captar la atención y la motivación necesaria para que el desarrollo de la clase sea fructífero, realizar más retroalimentaciones para analizar los resultados de nuestra clases en conjunto. Para afianzar aún más nuestros conocimientos y mejorar día a día nuestras prácticas pedagógicas, que constantemente se deben mejorar e ir creciendo como profesionales. El crecer como profesional permite que los estudiantes obtengan lo mejor de cada una de nosotras, realizando clases más diversificadas, enfocadas en que cada uno de los estudiantes aprendan, crezcan y se puedan desenvolver de mejor manera. (Informe EC, Equipo $\mathrm{N}^{\circ}$ 2)

\subsection{Trabajo colaborativo}

En los relatos de las participantes, el trabajo colaborativo constituye el descriptor más relevante del proceso de EC, el aspecto que más valoran de la experiencia vivida, el principal facilitador, y un elemento distintivo de las prácticas pedagógicas inclusivas. En términos generales, es significado como una relación entre sujetos iguales y diferentes, que en base a propósitos compartidos, coordinan sus acciones y esfuerzos según ciertas reglas interaccionales ${ }^{1}$ que legitiman a los participantes y definen un "nosotros", producen satisfacción y los conducen a lograr dichos propósitos.

Una primera distinción que emerge dice relación con los niveles de este trabajo colaborativo, diferenciándose el trabajo realizado en el proceso de EC (denominado "trabajo colaborativo real" por una de las participantes), de otras experiencias de trabajo colaborativo que suelen darse en su práctica pedagógica habitual, como en el caso de la relación establecida en el ejercicio de los roles tradicionales entre docente encargada del curso y educadora diferencial como profesional de apoyo. Acá el sentido profundo del trabajo colaborativo radica en compartir saberes, estrategias y experiencias vinculadas a la práctica pedagógica, lo que resulta útil y pertinente al propósito de su mejora, al mismo tiempo que genera un sentimiento de mayor valoración por parte de las participantes. Una educadora lo expresa así:

$$
\begin{aligned}
& \text {...yo siempre lo que más valoro, lo que hemos pedido acá en el colegio de hecho, es el } \\
& \text { trabajo colaborativo real..., que nos juntemos a hablar sobre experiencias pedagógicas, } \\
& \text { que no sea un trabajo administrativo, o sea, cómo lo haces tú en el inicio, cuál es tu } \\
& \text { idea, por ejemplo, en mi caso, para que los niños respeten las normas de convivencia...y } \\
& \text { aprender obviamente de la experiencia de mis colegas. (D, } \left.3^{\circ} \mathrm{B}, \mathrm{E} 1\right)
\end{aligned}
$$

Asimismo, el trabajo colaborativo promueve relaciones dialógicas entre los participantes, que expresan paridad y complementariedad interdisciplinaria de roles y funciones, que posibilitan un trabajo coordinado en equipo, reconoce el aporte y reafirma las distintas capacidades y experticias. Ello supone ampliar las posibilidades de aprendizaje. Al planificar, observar y retroalimentarse, las participantes pueden descubrir lo que las otras piensan o hacen distinto y similar, intercambiar aportes técnicos, sintiendo que sus ideas y contribuciones son consideradas.

Lo que si me sirvió mucho obviamente fue haber trabajado colaborativamente con mi compañera..., entre las dos nos pudimos complementar y pudimos enriquecer nuestras prácticas pedagógicas..., o sea, en primera instancia fue más o menos mostrarle a ella lo que hacía yo en mis clases, cómo hacía mis clases, y ella me observó..., entonces

\footnotetext{
${ }^{1}$ Desde la teoría de sistemas, el concepto de reglas interaccionales alude a los patrones recurrentes de relación que prescriben lo que se puede o no hacer, dándole predictibilidad a los comportamientos entre las personas en grupos con historia (familias, grupo curso, etc.) (Hernández, Vöhringer y Espinoza, 2004).
} 
después las dos nos juntamos, analizamos lo que había pasado, yo creo que la segunda clase pudimos hacerla un poquito mejor, ya que teníamos las dos perspectivas o los dos puntos de vista, y ella también pudo aportar mucho a mi trabajo. (D, $\left.3^{\circ} \mathrm{B}, \mathrm{E} 1\right)$

El establecimiento de vínculos de reciprocidad y reconocimiento entre las participantes, que incluyen actitudes y conductas de validación del otro, tales como respeto, empatía, confianza, comunicación asertiva, el refuerzo por lo que se hace bien. Esto es, una disposición de apertura hacia el otro que, a medida que transcurre el proceso, disipa temores, inseguridades y, por el contrario, facilita mostrar lo que se piensa o hace, escucharse, preguntar, declarar "no saber", recibir ayuda, o resolver dificultades. Todo ello, a su vez, favorece la misma competencia de trabajar colaborativamente.

... ella me decía P. tenemos que hacer esto, porque asi trabajamos nosotras..., y al final, ya después de esto (el EC), P., ¿̨cómo podemos trabajar esto?, o sea, la disposición igual cambió harto, cambiamos las dos, las dos como que crecimos, dijimos ya, hagamos esto, ¿̇cómo lo podemos hacer?..., con la segunda clase ya estábamos bien con la profe, me sentía bien porque me di cuenta que lo mío podía aportar.... (ED, $4^{\circ} \mathrm{B}$, E2)

Estos hallazgos son consistentes con las referencias al Trabajo Colaborativo señaladas en los documentos analizados, donde es valorado como uno de los principales facilitadores del EC:

Fue importante la realización del presente trabajo, ya que se pudo valorar como primera instancia, el trabajo colaborativo, que, en este grupo de docentes, tuvo mucho peso, ya que tuvimos que turnarnos, ponernos de acuerdo y consensuar ideas para lograr el objetivo. Como reflexión, nos permitió observarnos entre nosotros mismos, confiar en el compañero de trabajo y hacer causa común, para permitir mejorar nuestra labor docente. Pocas veces, contamos con la oportunidad de que otros pares, puedan retroalimentar nuestro trabajo, de forma constructiva- participativa. (Informe EC, Equipo $\mathrm{N}^{\circ}$ 1)

\subsection{Mejora de la respuesta educativa a la diversidad en el aula}

Desde los discursos de las docentes se desprenden ciertos rasgos distintivos que atribuyen a una práctica educativa que tiene en cuenta la diversidad y promueve que todos los estudiantes participen y se beneficien de las experiencias de aprendizaje que les ofrecen. Estos se sintetizan en cuatro aspectos que se describen a continuación y que son percibidos por las participantes como elementos significativos para proporcionar una respuesta más pertinente y efectiva a la diversidad en el aula.

Respecto de la comprensión acerca de la noción de diversidad, las entrevistas e informes analizados muestran que las conversaciones que se abrieron durante el proceso de EC respecto de sus estudiantes ayudaron a ampliar la mirada sobre la diversidad.

\subsection{Significados sobre diversidad}

La diversidad desde distintos puntos de vista, es reconocida como un valor constitutivo de una práctica inclusiva, permeando el discurso educativo sin que necesariamente exista un entendimiento compartido sobre sus significados. En este sentido, el análisis realizado a las entrevistas da luces de como interpretan este concepto y lo vinculan con la inclusión, desde la toma de conciencia de su complejidad como proceso que se construye en colaboración.

To siento que todos hablan de diversidad, todos hablamos de diversidad, pero estamos en un proceso, tenemos que empezar a hablar de inclusión, y ser realmente inclusivos..., porque si no, uno construye sola, pero es bueno también entre todos 
empezar a hablar un lenguaje en común, empezar a construir, y eso te lo dio este trabajo colaborativo. $\left(\mathrm{ED}, 3^{\circ} \mathrm{B}, \mathrm{E} 1\right)$

Desde otra perspectiva, se observa que los docentes tienden a relacionar la noción de diversidad con las diferencias individuales con que los estudiantes enfrentan su proceso educativo, en cuanto a capacidades, estilos y ritmos de aprendizaje, y como la tarea del docente implica hacerse cargo del aprendizaje de todos considerando a la vez sus singularidades.

Obviamente que todos los niños aprenden de diferente manera, todos son diferentes, incluso el niño que tiene mayor capacidad, también es distinto y él también necesita aprender ..., yo los veo asi a mis niños..., y trato de poder hacer mi clase para todos, pero siempre fijándome en la diversidad. $\left(\mathrm{D}, 3^{\circ} \mathrm{B}, \mathrm{E} 1\right)$

$\mathrm{Al}$ mismo tiempo, para algunas docentes la experiencia del EC les ayudó a ampliar su visión de la diversidad más allá de lo estrictamente relacionado con las características y necesidades educativas de los estudiantes, destacando la importancia de tomar en cuenta también, las diversas características y estilos de enseñanza de los profesionales.

...mirar la diversidad como un todo es importante, (...) no solo enfocar la diversidad en los estudiantes sino también en la diversidad profesional. (EP, Kinder, E2)

Los relatos de las docentes aluden a las oportunidades de dialogo y reflexión sobre la diversidad que se generaron durante el proceso de EC y que les permitió afinar y profundizar la mirada respecto de las diferencias de sus estudiantes y compartir estrategias para abordarlas.

\title{
4.5. Conocimiento del curso y sus estudiantes
}

Los discursos de las docentes muestran un alto grado de convergencia en torno a la relevancia que le asignan al conocimiento del contexto de aula y a las particularidades del grupo de estudiantes con el que lleven a cabo el EC, y como este conocimiento es gravitante para que las decisiones curriculares que adopten sean más pertinentes a las diversas necesidades educativas de los estudiantes.

\begin{abstract}
Afortunadamente yo también venía con este grupo-curso desde primero básico, por lo tanto..., yo ya sé casi al cien por ciento cómo trabaja mi curso. Es que para mí es súper importante..., porque no todos los niños son iguales, no todas las estrategias o las metodologías funcionan para todos los cursos, aunque sean del mismo nivel. To creo que facilita mucho cuando uno ya conoce al curso..., frente a llegar inesperadamente y planificar sin conocer a los niños, el contexto, sin saber las necesidades que requiere el grupo curso. $\left(\mathrm{D}, 4^{\circ} \mathrm{B}, \mathrm{E} 2\right)$
\end{abstract}

Más específicamente, refieren a que una enseñanza atenta a la diversidad es aquella que pone en el centro a los estudiantes. Es decir, que tiene en cuenta los conocimientos, habilidades y formas de aprender de los estudiantes a la hora de planificar y desarrollar la clase, de manera que todos tengan, en la mayor medida posible, oportunidad de participar y aprovechar las experiencias de aprendizaje. A su vez, la respuesta de los estudiantes se convierte en un llamado de atención respecto de los ajustes o mejoras que son necesarios introducir.

Que en mi clase estén presente los diferentes estilos de aprendizaje, yo los conozco, yo sé cómo aprenden, por ejemplo, mostrarles un video, leer algo, hacer una representación, un dibujo, un trabajo en grupo..., es lo que trato de hacer en mis clases. $\Upsilon$ eso fue lo que más nos dificultó, la obra (de teatro) en primera instancia era muy difícil, era muy larga, fue lo que cambiamos (para la segunda clase) porque no nos habia resultado. $\left(\mathrm{D}, 3^{\circ} \mathrm{B}, \mathrm{E} 1\right)$ 


\subsection{Variadas estrategias y recursos didácticos}

En concordancia con lo anterior, la totalidad de las docentes entrevistadas sostienen que una condición esencial para dar respuesta a la diversidad es conocer bien a los estudiantes y las dinámicas que se dan en aula para, a partir de ello, poner en juego variadas estrategias y recursos de enseñanza que conecten con las necesidades de aprendizaje de los estudiantes.

$$
\text { ...el objetivo es que todos aprendan y no sólo algunos. (D, } \left.4^{\circ} \mathrm{B}, \mathrm{E} 2\right)
$$

Las descripciones que realizan las docentes develan intencionalidad y búsqueda para hacer algo diferente que rompa con la práctica habitual. En este sentido, para las participantes dar respuesta a la diversidad implica interactividad, una práctica con mayores niveles de flexibilidad, que ofrece posibilidades de experimentar situaciones donde los estudiantes se involucran activamente, haciendo el aprendizaje más significativo al vincularlo con sus intereses y experiencia, y construirlo en forma colaborativa.

Para mí lo importante es el desarrollo de la clase porque ahí uno tiene que buscar las estrategias para explicarle el contenido a los estudiantes porque si no aprenden con una, tenemos que empezar a ver qué otra estrategia, en el mismo momento..., para que los chiquillos puedan entender. (ED, Kinder, E2)

\subsection{Interacciones colaborativas en el aula (entre docentes y estudiantes, entre estudiantes)}

El tipo de relación que establecen los docentes con los estudiantes y las interacciones que promueven en el aula, son percibidas como un aspecto crucial de una práctica que acoge la diversidad. El clima del aula y la "disciplina", representada en el respeto a las normas de convivencia, la disposición al diálogo y la búsqueda conjunta de soluciones a los problemas, son actitudes que destacan en tanto propician condiciones favorables al aprendizaje y a la introducción de innovaciones en las practicas pedagógicas.

\section{A veces incluso cuando ha habido problemas serios de conducta..., empezamos a conversar y puedo estar una hora de clases conversando..., trabajando con los niños sobre qué podemos hacer para mejorar esto..., cómo lo podemos hacer. (EP Kinder, E2)}

Las docentes reconocen la considerable influencia que tienen las interacciones que se dan en el aula en el aprendizaje y participación de los estudiantes y como las observaciones y análisis de las clases realizadas, les permitió repensar su práctica. Destacan que colocar el foco en la participación contribuyó a este propósito. Así, el EC les permitió poner atención en el nivel y formas de participación que suelen darse al interior del aula, en quienes exhiben mayor y menor participación, hipotetizar respecto de los factores que pudieran estar incidiendo en el grado de participación y en las estrategias que podrían incentivarla. Por ejemplo, a través de la realización de "preguntas amables":

$$
\begin{aligned}
& \text {... después, dije (a la colega) sabes que tenemos que cambiar la forma de la pregunta, } \\
& \text { que sea más amable y que a lo mejor los otros chicos, tal y tal..., que yo no los conocía } \\
& \text { en un contexto mayor, también pudiesen participar, entonces cuando yo empecé a } \\
& \text { realizar las preguntas me dirigí más a ellos, "¿̀y qué piensa usted?, ¿̇qué piensa usted?, } \\
& \text { ¿y usted? (ED, } \left.3^{\circ} \mathrm{B}, \mathrm{E} 1\right)
\end{aligned}
$$

Por su parte, las interacciones entre los estudiantes cobran sentido en la medida que las actividades involucran aprendizaje cooperativo y apoyo mutuo entre estudiantes, en un intento de superar la tendencia a la enseñanza transmisiva y el excesivo trabajo individual que limita las posibilidades de convivencia y el desarrollo de actitudes colaborativas. Así, 
las docentes relatan como el EC les ayudó a introducir cambios en la estructura habitual de la clase, incorporando el trabajo en pequeños grupos o en duplas, y como ello contribuyó a una mayor participación e involucramiento de los estudiantes en las actividades. Así como también, a expandir las oportunidades de aprendizaje al favorecer la enseñanza entre pares.

\begin{abstract}
Porque los niños en la primera (clase) querían juntarse todos con sus amiguitos. "Ay profesora, ¿̇no me puedo sentar con no sé quién?" Prefiero que se siente acá porque también hay niños que requieren de su ayuda, yo necesito que la apoyes más a ella porque es más tímida, vamos a hacer un trabajo que les vamos a explicar, pero necesito más de su ayuda en este grupo. $\left(\mathrm{D}, 4^{\circ} \mathrm{B}, \mathrm{E} 2\right)$
\end{abstract}

\title{
4.8. Escuchar a los estudiantes y tener en cuenta sus opiniones
}

Dentro del proceso del EC la consideración de las voces de los estudiantes, es una de las estrategias que concitó mayor interés en algunas docentes por considerarse una práctica novedosa y poco habitual, pero necesaria en la medida que el objetivo principal de la práctica inclusiva es mejorar los niveles de participación y aprendizaje de todos los integrantes del grupo. Una profesora comenta lo que les planteo a sus estudiantes:

... todas las opiniones son importantes, todo es valioso, entonces yo quiero escucharte a ti..., porque yo sé que lo que usted va a decir es muy importante, lo que usted crea y ahí ellos empezaron a hablar. $\left(\mathrm{ED}, 3^{\circ} \mathrm{B}, \mathrm{E} 1\right)$

$\mathrm{Al}$ respecto, cabe destacar que, en dos de los tres equipos de $\mathrm{EC}$ estudiados, las docentes hacen referencia a las acciones que implementaron para recabar la opinión de los estudiantes con el propósito de conocer sus puntos de vista y desde allí enriquecer la experiencia de aprendizaje para una siguiente clase.

... en la primera clase yo les entregué un post-it y ellos tenían que poner qué les había parecido la clase..., lo que habíamos trabajado, y después lo pegamos en la pizarra, y yo iba leyendo algunos..., y después decidimos hacerlo levantando la mano y enfocándonos más en el trabajo en grupo, no a la experiencia en sí en la clase entera, sino ¿̇te gustó trabajar en grupo?, ¿̨por qué, ¿̇cómo te gustaría trabajar la próxima clase? $\left(\mathrm{D}, 3^{\circ} \mathrm{B}, \mathrm{E} 1\right)$

Al contrastar las referencias a la mejora de la respuesta educativa a la diversidad que las docentes señalan en sus reportes escritos del EC, estas muestran alta consistencia con los hallazgos que se desprenden del análisis de las entrevistas, en especial con relación a las categorías: variadas estrategias y recursos didácticos, conocimiento de alumnos e interacciones entre estudiantes en el aula, como se puede apreciar en la siguiente narrativa:

Las actividades utilizadas facilitaron la participación de todo el curso ya que escogimos diferentes estrategias para favorecer la participación y promover el trabajo en grupo. Los estudiantes estaban motivados y con ganas de trabajar. Las actividades propuestas fueron lúdicas y planteadas para poder trabajar los diferentes estilos de aprendizaje".

Ejemplos de las actividades referidas:

"Los estudiantes después de completar el mapa del personaje pudieron escoger diferentes materiales para representar al personaje que más les gustó o les llamó la atención.

Los estudiantes trabajaron en grupos de cinco integrantes.

Los estudiantes escogieron libremente el personaje de acuerdo a sus gustos y habilidades.

Confeccionaron máscaras de los personajes utilizando diferentes materiales en la clase de educación artística. 
Leyeron la obra y la presentaron frente al curso utilizando las máscaras que confeccionaron.

Las preguntas de metacognición las podían responder oralmente o escritas.

Escribieron en un post it la respuesta de la siguiente pregunta: ¿ Cómo te gustaría trabajar en la próxima clase? (voces de los estudiantes). (Informe EC, Equipo $\mathrm{N}^{\circ}$ 1)

\subsection{Factores facilitadores del proceso de EC:}

Las apreciaciones de las docentes respecto de los factores tanto personales como del contexto que facilitan el proceso de EC, remiten en primer lugar al "Trabajo Colaborativo", referido anteriormente. Le sigue en importancia una "Actitud favorable hacia el aprendizaje y el desarrollo profesional", esto es, un cuerpo de creencias, sentimientos y conductas que trasuntan una predisposición personal favorable hacia la experiencia del EC, y que se expresa en apertura al aprendizaje, motivación para abordar y superar dificultades, dedicación de tiempos personales, involucración en el proceso, deseo de obtener resultados positivos en beneficio de los alumnos.

To creo que la disposición de las dos..., porque también tuvimos que juntarnos, para hacer el trabajo tuvimos que utilizar tiempo aparte. (ED, $\left.4^{\circ} \mathrm{B}, \mathrm{E} 2\right)$

Otro facilitador dice relación con el "Aporte técnico", es decir, con las competencias y experiencia acumulada en las trayectorias profesionales de las participantes, que se pusieron en juego en el transcurso del proceso. Se incluye aquí la preparación previa en la metodología del EC, el dominio de contenidos disciplinares o de diversas técnicas y recursos metodológicos que facilitan la participación y expresión de los alumnos, así como la capacidad para observar y visibilizar las particulares habilidades de los estudiantes. A la base de esto se encuentra un reconocimiento de los propios saberes (lo que yo sé o no sé hacer) y de los del otro y, por tanto, también una estimación de lo que puedo enseñar o aprender del otro.

E. me enseñó, yo igual sabía un poco de los estilos, pero ella conoce mucho mejor que yo, trabajar con diferentes estilos de aprendizaje en la misma clase, porque yo también lo trato de hacer pero, por ejemplo, en una clase vemos un video, en otra clase hacemos una representación, en otra clase hacemos una lectura, yo creo que eso también fue lo que aprendí, o sea, como a hacer todo en la misma clase.... (D, $\left.3^{\circ} \mathrm{B}, \mathrm{E} 1\right)$

Por otra parte, las docentes refieren al "Apoyo Institucional" como un facilitador de contexto relevante para el proceso de EC. Al respecto contar con el apoyo de los directivos en términos de la disponibilidad de tiempo, coordinación de horarios, entre otras actividades cotidianas. Esto se relaciona con cierta cultura del establecimiento educacional proclive a facilitar instancias de perfeccionamiento profesional.

\subsection{Factores obstaculizadores del proceso de EC}

Las participantes perciben como principal obstáculo para la implementación del proceso del EC la "Falta de Tiempo", aludiendo a escasa disponibilidad de oportunidades para reunirse y trabajar en las tareas propias de las distintas etapas del proceso, debido a la estricta organización del tiempo en que transcurre la vida escolar, a jornadas laborales de las docentes que no coinciden en los horarios. También significa una cierta vivencia de exigencia y apremio, manifestándose la sensación que con más tiempo hubieran podido conseguir mejores resultados, ya sea debido a una mejor retroalimentación, o a una planificación más acabada de las clases. 
Acá fue el tiempo, o sea la época en la que lo hicimos..., fue como a final de semestre. Estábamos evaluando, estábamos haciendo ensayos de graduación, estábamos en mil cosas..., porque quizás habría sido más enriquecedor que nos juntáramos con más tiempo, que lo analizáramos a profundidad... (EP, Kinder, E2)

Otro obstaculizador es el desconocimiento de los alumnos, de la dinámica del curso, o del nivel (si son párvulos, o de primer ciclo básico). Lo es en tanto el conocimiento de los estudiantes del curso y su forma de funcionamiento es un aspecto que entienden crucial para una práctica pedagógica inclusiva. De hecho, es definido como un importante facilitador.

$\mathrm{Al}$ contrastar estos resultados con lo referido en los informes del EC, se aprecia una correspondencia que los reafirma. Por ejemplo, sostienen que las desventajas o dificultades encontradas en el proceso de EC giran en torno al saber previo con el que enfrentan la planificación, así como la gestión del tiempo y recursos:

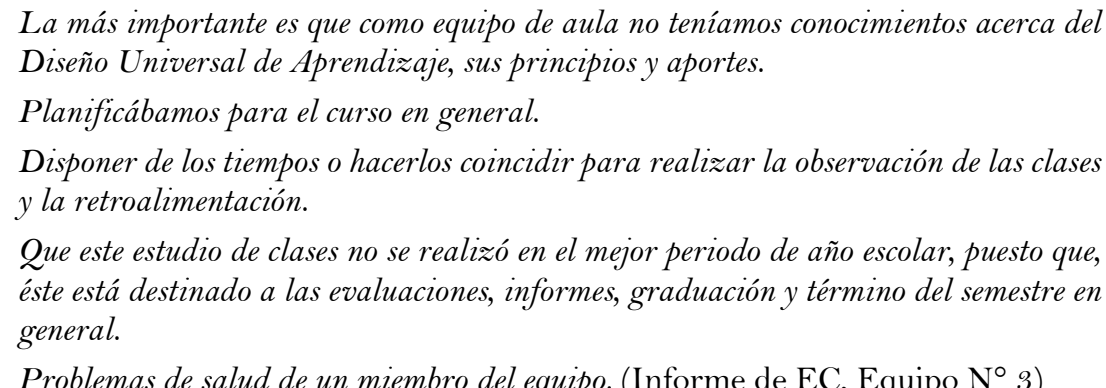

\subsection{EC favorece el desarrollo profesional}

Los discursos de las participantes aportan evidencias de que el EC posibilitó su desarrollo profesional docente, particularmente en lo que respecta a la mejora de las prácticas pedagógicas involucradas en el diseño e implementación curricular con foco en la diversidad. Ello, en la medida que los procesos de reflexión acción colaborativos, llevados a cabo desde los propios saberes y prácticas de atención a la diversidad, les permitieron revisarlas y perfeccionarlas de una clase a otra, a la luz de la retroalimentación derivada de la observación entre pares.

Yo creo que lo voy a instaurar, porque me pareció entretenido..., más coherente, entonces también fue un enganche decir cosas súper concretas..., porque uno habla, habla de cosas, pero a ver, cómo llevamos toda esta teoría a la práctica, y eso es súper difícil también... (ED, $\left.3^{\circ} \mathrm{B}, \mathrm{E} 1\right)$

De esta forma, se desprende que la dinámica del EC favorece el desarrollo de habilidades relevantes para la formación de profesionales reflexivos y, por consiguiente, contribuye a la construcción de un pensamiento y práctica pedagógica inclusiva.

Aprender a analizar la práctica educativa, buscar retroalimentación, tener apertura
a trabajar colaborativamente para la mejora de la misma, todo en beneficio del
aprendizaje de los alumnos. $\left(\mathrm{ED}, 4^{\circ} \mathrm{B}, \mathrm{E} 2\right)$
..porque después de las observaciones que hicimos de nuestras clases pudimos
determinar cuáles fueron las cosas en que fallamos y cuáles fueron las cosas que
resultaron exitosas para poder después repetirlas o modificarlas. $\left(\mathrm{D}, 4^{\circ} \mathrm{B}, \mathrm{E} 2\right)$

$\mathrm{Al}$ mismo tiempo, incide en la visión de sí mismo en términos profesionales y personales, lo que se relaciona con la sensación de mayor eficacia que manifiestan algunas docentes, así como a una disposición a seguir aprendiendo. También se expresa en la visión de sí mismos como reflejo de las relaciones con los pares, y que aluden a intentos de ser más 
tolerantes con los otros y establecer relaciones de confianza, de mayor apertura y disposición a los demás, habilidades necesarias para el trabajo colaborativo en el que se sustenta el EC y que consecuentemente contribuye a desarrollar.

... la disposición, el querer escuchar, el querer preguntar y que uno pudiese preguntar cosas técnicas, "oye, ¿̇cómo se hace la metacognición?", que siempre me dicen cuándo van al aula "está mala", y digo mira, sabes qué, yo creo que esto y esto otro podría ser, ¿te parece que lo probemos, ya? me dijo, porque todos me hablan..., mis cierres no son buenos, pero nunca nadie me ha dicho cómo hacer un cierre. $\left(\mathrm{ED}, 3^{\circ} \mathrm{B}, \mathrm{E} 1\right)$

En la triangulación de las apreciaciones de las participantes en relación a EC y Desarrollo Profesional, con el análisis documental, se aprecian significaciones similares, tal como lo ilustra el siguiente texto sobre las ventajas experimentadas por un equipo:

Ventajas:

- Las planificaciones las realizamos colaborativamente.

- Las actividades fueron planificadas en conjunto, analizadas y evaluadas.

- Las observaciones realizadas sirvieron para retroalimentar y mejorar las actividades y estrategias utilizadas.

- Pudimos compartir nuestros conocimientos y así mejorar nuestras prácticas pedagógicas.

- Pudimos retroalimentar gracias a la observación, conociendo nuestras debilidades y fortalezas.

- Evaluamos las actividades en equipo, tomando en cuenta nuestro trabajo y el de los estudiantes.

- Dialogamos para resolver conflictos y ponernos de acuerdo.

- Intercambiamos opiniones y puntos de vista. (Informe EC, Equipo $\mathrm{N}^{\circ} 1$ )

A propósito de los hallazgos hasta aquí expuestos, en las docentes se aprecia una opinión favorable respecto de posibilidades de aplicación futuras del EC, en la perspectiva de expandir esta metodología en sus propias escuelas, o a otros establecimientos de la comuna:

\footnotetext{
Nosotros lo queremos aplicar acá..., o sea que yo vaya a la clase de otra colega..., de mí mismo ciclo, y hacer algo muy parecido a lo que se hace acá, o sea, una retroalimentación, aunar criterios..., sacar ideas, conversar, eso se quiere hacer acá, yo creo que es muy factible que se haga..., que si tuviéramos el tiempo, y todo lo que necesitamos, yo creo que lo haríamos encantadas de la vida, tenemos mucha motivación..., siempre queremos innovar, tratamos de conversar entre nosotras, y siempre es voluntariamente, porque no hay tiempo para hacerlo y yo creo que si se podría implementar algo como esto acá. $\left(\mathrm{D}, 3^{\circ} \mathrm{B}, \mathrm{E} 1\right)$
}

Adicionalmente, algunas docentes, junto con desear que el EC se amplíe y llegue a más docentes, a la luz de la experiencia vivida y de la realidad de sus escuelas, aluden a dos tipos de consideraciones que sería recomendable tener presente en futuras aplicaciones.

Aquellas que se relacionan con la acción formativa propiamente tal: contar con conocimientos básicos sobre la metodología de EC y su vinculación con desarrollo curricular y la práctica inclusiva, aumentar el número de clases del ciclo EC, elegir el periodo del año más apropiado para su implementación.

To creo que sí podría resultar, pero primero habría que capacitar a la gente, tiene que conocer de lo que estamos hablando, por ejemplo, nosotros pudimos encontrar soluciones, nuevas estrategias, incorporar, pero en base a lo que habiamos aprendido. (EP, Kinder, E2) 
Aquellas que se vinculan con las facilidades y apoyos institucionales que un proceso colaborativo de reflexión acción como este requiere: disponibilidad de tiempo, organización de horarios que sean compatibles con el proceso, apertura del aula a otros profesionales, equipos de $\mathrm{EC}$ conformados por profesionales que tengan conocimiento previo de los alumnos del curso donde se llevará a cabo el EC.

Lo fundamental es dar el tiempo para poder hacerlo, planificarlo y hacer después la retroalimentación, todo va en el tiempo (...) el tiempo de la retroalimentación es súper importante después de la observación de clase, cosa que por lo general no se puede hacer, netamente por un tema de colegio, de horas, de tiempo. (D, $\left.4^{\circ} \mathrm{B}, \mathrm{E} 2\right)$

\section{Discusión}

Este estudio se enmarca dentro de la línea de investigación relacionada con la formación y desarrollo profesional docente, específicamente en el ámbito de la práctica inclusiva y la respuesta a la diversidad en el aula.

En relación a hallazgos previos, que han fundamentado los aportes de las distintas expresiones internacionales del EC para el aprendizaje en diversas materias (Soto y Pérez, 2015), esta investigación añade evidencia específica de la pertinencia del EC respecto de la mejora de la respuesta educativa a la diversidad en el aula en el contexto específico de escuelas públicas de Santiago de Chile, tal como también fue demostrado por Messiou y colaboradores (2016) en algunos países europeos.

Según Soto y Pérez (2015), los distintos formatos del EC se componen tanto de un proceso de trabajo para la mejora de la práctica pedagógica (el diseño, desarrollo, comprobación, crítica y mejora de una propuesta didáctica experimental), como de un sistema de aprendizaje de los docentes. Estos elementos se develan fundamentales en las significaciones y alta valoración de las participantes, en tanto sostienen por un lado que les ha ayudado a explorar nuevas estrategias para atender la diversidad, independientemente de los contenidos curriculares abordados por cada equipo. Por otro lado, el reconocimiento de un sistema de aprendizaje esencialmente colaborativo, una relación dialógica exotópica entre sujetos "iguales y diferentes" según las formulaciones de Torodov (1981, citado en Molina y Serrano, 2016), que surge desde sus diversos saberes y experiencias, y responde a sus necesidades o problemas identificados conjuntamente. Según Gallego, Jiménez y Corujo (2018), para que se produzca un aprendizaje entre iguales en relación a un objetivo conocido y compartido, las tareas deben ser significativas y conectar con las necesidades de las personas implicadas otorgándole un sentido y constituyendo un recurso que atiende a aquellas necesidades.

Desde otra perspectiva, los hallazgos respecto de la valoración y los aportes del trabajo colaborativo del EC focalizado en la respuesta a la diversidad, se corresponden con el conocimiento ya sólidamente fundamentado sobre la importancia de la colaboración y apoyo entre los distintos agentes educativos para la construcción de una educación inclusiva (Gallego, Jiménez y Corujo, 2018), así como de las variadas formas en que esta colaboración puede expresarse, incluyendo las distintas versiones del EC (Soto y Pérez, 2015), el Learning Study (Holmqvist, 2015), los Grupos de Ayuda Mutua (Gallego, Jiménez y Corujo, 2018), las Parejas Pedagógicas (Cotrina, García y Caparrós, 2017), entre otros. Expresiones todas que contrarrestan el habitual aislamiento con que el docente lleva a cabo la enseñanza, planificada individualmente y realizada en la soledad del aula, bajo el supuesto de un saber experto. Sin embargo, en el caso de la atención a la 
diversidad, la generalidad de los docentes informan insuficiente preparación y capacitación para responder adecuadamente a las diferentes necesidades de todos los alumnos (Cisternas y Lobos, 2019; Duk, 2014; Zárate-Rueda, Díaz-Orozco y Ortiz-Guzmán, 2017), una necesidad a la que el proceso de EC aquí realizado dio una respuesta colaborativa.

Un punto que merece atención en los hallazgos del trabajo colaborativo, es la mayor valoración de la práctica colaborativa vivenciada en el proceso de EC que de la que resulta de la habitual relación de colaboración interdisciplinaria entre docentes y educadoras diferenciales o psicopedagogas, a propósito de la implementación del enfoque de coenseñanza impulsado por el Ministerio de Educación en el marco de los Programas de Integración Escolar (PIE) cuyo principal objetivo es apoyar la inclusión de los estudiantes con NEE en la escuela común. Esta apreciación crítica parece deberse en buena parte a que la tendencia ha sido a que las acciones de apoyo que estos profesionales ejercen se dirijan preferentemente a los estudiantes con NEE, beneficiarios directos de los PIE. El enfoque del EC, por el contrario, facilita la construcción de una relación profesional más horizontal, donde ambas partes se co-responsabilicen del proceso educativo del grupo/curso, en vez de funciones predefinidas que conllevan ciertas tensiones, y que no necesariamente adquieren sentido y responden a las necesidades de ambos profesionales. Las implicancias de este hallazgo, de corroborarse en estudios dirigidos específicamente al tema de la coenseñanza, podrían ser de interés para un mejor desarrollo de esta relación profesional promovida desde la política educacional chilena.

En tal sentido, el aprendizaje profesional que promueve la práctica del EC contribuye a superar el enfoque centrado en el alumno individual y sus dificultades. Como plantea Durán y Giné (2011), desde el enfoque inclusivo:

\begin{abstract}
No son tan importantes las condiciones de los alumnos cuanto la capacidad del centro educativo de acoger, valorar y responder a las diversas necesidades que plantea el alumnado; capacidad que debe reflejarse en el pensamiento del profesorado, en las prácticas educativas y en los recursos personales y materiales disponibles. (p. 165)
\end{abstract}

Con relación a la mejora de la respuesta a la diversidad, los hallazgos en su conjunto, dan cuenta de las oportunidades que proporciona el $\mathrm{EC}$ a los equipos implicados para detenerse a repensar y replantear conjuntamente las prácticas educativas, sacando a la luz el conocimiento (evidencias) de que disponen respecto de las condiciones del contexto de aula, las formas de enseñanza que habitualmente utilizan (Pérez, Soto y Serván, 2015), y en qué medida estas promueven la participación y aprendizaje de todos los estudiantes.

En consonancia con otras investigaciones publicadas por Ainscow y Messiou (2018) y Simón, Echeita y Sandoval (2018), una actividad clave que marca el punto de partida del proceso de reflexión acción, es el dialogo inicial en torno a la diversidad y sus expresiones en el curso donde se llevará a efecto el EC. Esta instancia es uno de los elementos distintivos de la propuesta de estos investigadores, tomando como referente la metodología de Lesson Study para el desarrollo de prácticas inclusivas situadas en contextos reales (Pérez y Soto, 2011; Simón, Echeita y Sandoval, 2018). Los hallazgos muestran la relevancia de este espacio de conversación que permite develar las concepciones de los docentes en relación a las nociones de diversidad e inclusión y compartir significados que ayuden a la construcción de un lenguaje común sobre la práctica inclusiva.

Previo a planificar colaborativamente la primera clase (lección experimental siguiendo a Pérez y Soto, 2011), las evidencias relevan la importancia de consensuar al interior del 
equipo el foco que guiará el diseño e implementación de la actividad curricular. En el caso de las escuelas chilenas los tres equipos estudiados optaron por concentrar la atención en el grado y calidad de participación de los estudiantes, fundado en la estrecha interrelación existente entre participación y aprendizaje (Ainscow et al., 2012) bajo la premisa de que una mayor y más activa participación en las actividades favorece mejores aprendizajes.

Otros dos elementos que destacan las investigaciones mencionadas y que tienen puntos de encuentro con los resultados del presente estudio, se relacionan con un cambio de mirada hacia los estudiantes y la consideración de sus voces dentro del ciclo de mejora del EC. Respecto del primer punto, los distintos estudios revisados que utilizan la metodología de EC, muestran que la reflexión sobre las concepciones y la práctica con foco en la diversidad, permite ampliar y afinar la mirada en torno las diferencias y visibilizar a estudiantes que no participaban, estaban ocultos o suelen pasar desapercibidos (Messiou et al, 2016; Simón, Echeita y Sandoval, 2018; Pérez y Soto, 2011).

Con relación al segundo aspecto, existen sólidas evidencias en relación al impacto que tiene un mayor protagonismo de los estudiantes en los procesos de mejora, al considerar sus puntos de vista en distintas fases del proceso de EC (Messiou et al, 2014). Estos aportes sumados a la positiva valoración de los equipos estudiados que exploraron de manera incipiente esta posibilidad, en tanto el EC objeto de este estudio no enfatizó en las voces de los estudiantes, llevan a considerar seriamente la posibilidad de intencionar el uso de este recurso en futuras experiencias de EC. Las evidencias de la investigación internacional al respecto, así como las reflexiones de las participantes ponen de relieve el valor que revisten las opiniones de los estudiantes acerca de la enseñanza y su utilidad para la revisión y mejora de la propia práctica, así como para propiciar un mayor involucramiento y compromiso de los estudiantes con su aprendizaje (Ainscow y Messiou, 2018; Susinos, Rojas y Lázaro, 2011).

Si bien los hallazgos de esta investigación aportan al conocimiento respecto de una formación docente orientada a la inclusión, desde una perspectiva sistémica se hace necesario considerar su contribución en un contexto más amplio. Por muy positiva que sea una experiencia formativa, sus repercusiones finales en los cambios culturales que se necesitan para cimentar las bases que faciliten un tránsito más seguro y prometedor hacia comunidades auténticamente inclusivas, dependen de la interacción de múltiples factores internos y externos a las comunidades educativas, tal como lo sostiene el concepto de "ecología equitativa" de Ainscow y otros (2013), para referirse al conjunto de procesos interrelacionados que inciden en la vida de la escuela.

\section{Conclusiones}

Los resultados derivados del análisis de los discursos de los docentes participantes, dan luces respecto de los significados y sentidos que le atribuyen al proceso de EC para el desarrollo de prácticas inclusivas, que den respuesta a la diversidad en el aula. Esta experiencia innovadora en el ámbito del desarrollo profesional docente en Chile, es valorada positivamente a propósito de los atributos que la distinguen de otras acciones formativas tradicionales, y de los beneficios que las docentes perciben que les aporta a su desarrollo personal y profesional.

En este sentido, la información recabada tanto de las voces de los participantes como de los antecedentes de la investigación internacional revisada, permite sostener que el EC es 
una estrategia con gran potencial para promover el desarrollo de un pensamiento y práctica pedagógica coherente con los principios de inclusión y el valor de la diversidad, toda vez que intenciona procesos colaborativos de reflexión acción situados en contextos reales, a partir de problemáticas vinculadas a la enseñanza definidas colectivamente para la mejora de la práctica educativa con foco en el aprendizaje y la participación de todos los estudiantes.

Se concluye, que lo más preciado por los docentes en su primera incursión en un proceso acotado de EC, es el "trabajo colaborativo real", significado como reciprocidad, reconocimiento, complementariedad, y un proceso de reflexión y construcción conjunta a partir de la práctica pedagógica, que involucra retroalimentación entre pares a partir de la observación de clases planificadas colaborativamente con foco en la atención a la diversidad y en la participación de todos/as. Cabe destacar que estos espacios de dialogo y reflexión pedagógica, orientados al enriquecimiento y diversificación curricular mediante un trabajo en triadas, son instancias privilegiadas para gatillar cambios a nivel de la organización del aula como de las estrategias y recursos didácticos, tal como se evidencia en esta experiencia.

Todo lo anterior permite concluir que el EC facilita el desarrollo profesional, en los términos específicos de aprendizajes y adquisición de nuevos recursos vinculados al saber y el saber hacer y, por tanto, al desarrollo de competencias profesionales, así como cambios favorables en la visión de sí mismo, la propia valoración y sentimiento de eficacia personal, aspectos relevantes para el quehacer profesional. En este caso, para una mejor respuesta a la diversidad en el aula.

Por otra parte, la investigación permitió identificar algunos factores críticos que a juicio de los participantes es necesario de tener en cuenta para el éxito de futuras acciones formativas en base a esta metodología y que resultan orientadoras. Con relación a la acción formativa propiamente tal destacan: la importancia de contar con conocimientos previos sobre la metodología de EC y su vinculación con desarrollo curricular y la práctica inclusiva, aumentar el número de clases del ciclo EC, considerar el periodo del año escolar más apropiado para su implementación. Un segundo tipo de consideraciones se asocian al apoyo institucional que un proceso colaborativo de reflexión acción requiere: disponibilidad de tiempo, organización de horarios que sean compatibles con el proceso, apertura del aula a otros profesionales, equipos de EC conformados por profesionales que tengan conocimiento previo del grupo/curso donde se llevará a cabo el ciclo de EC y que estén dispuestos a participar de un trabajo colaborativo.

Una limitación de la presente investigación, es que estuvo acotada a un grupo de docentes y a las textualidades derivadas de entrevistas y registros escritos. La consideración de otros actores relevantes, como los directivos y, en particular, los estudiantes en tanto destinatarios directos de la experiencia, podrían aportar a una visión más amplia y completa de la contribución del EC y sus implicancias para el desarrollo de prácticas inclusivas. En este sentido, sería recomendable para futuras investigaciones incluir a otros actores clave como los aquí señalados. En la misma línea, aplicar la metodología del EC en otros niveles y contextos, por ejemplo, docentes de educación media o de educación superior. Ello permitiría apreciar cuáles son los alcances y limitaciones en estos otros escenarios.

Por otra parte, la incorporación de los puntos de vista de los estudiantes en las distintas fases del ciclo del EC es un desafío pendiente, que se proyecta como una interesante línea 
de investigación e innovación destinada a fortalecer los procesos de reflexión para la mejora de la enseñanza. Esta propuesta se asienta en el interés que esta acción despertó en los docentes que experimentaron algunas estrategias para recoger las voces de sus estudiantes, concluyendo que se trata de una práctica novedosa muy poco habitual, pero muy necesaria si entendemos que una práctica inclusiva se preocupa de fomentar la participación de todos/as.

Complementariamente, sería importante explorar otras versiones de EC que consideren más ciclos de planificación, observación/implementación, y retroalimentación, o más permanencia en el tiempo, podrían aportar conocimiento sobre cuánto más pueden favorecer los resultados, o sobre lo mínimo que se requiere para consolidar aprendizajes y cambios en la práctica, todo ello en favor de la utilización más eficiente de los recursos educativos.

Finalmente, los resultados de la presente investigación aportan desde las voces de los propios actores, al ámbito específico de los modelos o estrategias que promueven el desarrollo profesional docente, de cara a los desafíos actuales que demandan las políticas públicas de inclusión y el nuevo sistema nacional de desarrollo profesional docente, recientemente implementado en Chile en el marco de la reforma educacional, elementos relevantes en el tránsito hacia una educación inclusiva, equitativa y de calidad para todos y todas.

\section{Referencias}

Ainscow, M. (enero, 2005). El próximo gran reto: La mejora de la escuela inclusiva. Presentación de apertura del Congreso sobre Efectividad y Mejora Escolar. Universitat de Barcelona, España. https://doi.org/10.1007/s40841-016-0056-x

Ainscow, M. (2016). Diversity and equity: A global education challenge. New Zealand Journal of Educational Studies, 51(2), 143-155. https://doi.org/10.1080/13632434.2012.669648

Ainscow, M. y Messiou, K. (2018). Engaging with the views of students to promote inclusion in education. Journal of Educational Change, 19(1), 1-17. https://doi.org/10.1007/s10833-017-9312-1

Ainscow, M., Dyson, A., Goldrick, S. y West, M. (2012). Making schools effective for all: Rethinking the task. School Leadership \& Management, 32(3), 1-17

Ainscow, M, Dyson, A., West, M. y Goldrick, S. (2013). Promoviendo la equidad en la escuela. Revista de Investigación en Educación, 11 (3), 44-56.

Blanco, R. (2014). Inclusión educativa en América Latina: Caminos recorridos y por recorrer. En A. Marchesi, R. Blanco y L. Hernández (Eds.), Avances y desafíos de la educación inclusiva en Iberoamérica (pp.11-35). Fundación MAPFRE.

Barboza, J. y Zapata, A. (2013). El estudio de clase: Estrategia y escenario para la cualificación del profesor de matemáticas. Formación Universitaria, 6(4), 49-62. https://doi.org/10.4067/So718-50062013000400006

Cisternas, T. y Lobos, A. (2019). Profesores nóveles de enseñanza básica: Dilemas, estrategias y obstáculos para abordar los desafíos de una educación inclusiva. Revista Latinoamericana de Educación Inclusiva, 13(1), 37-53. https://doi.org/10.4067/So718-73782019000100037 
Cotrina, M., García, M. y Caparrós, E. (2017). Ser dos en el aula: Las parejas pedagógicas como estrategia de coenseñanza inclusiva en una experiencia de formación inicial del profesorado de secundaria. Aula Abierta, 46, 57-64. https://doi.org/10.17811/rifie.46.2.2017.57-64

Chong, W. H. y Kong, C. A. (2012). Teacher collaborative learning and teacher self-efficacy: The case of lesson study. The Journal of Experimental Education, 80(3), 263-283.

https://doi.org/10.1080/00220973.2011.596854

Duk, C. (2014). La formación y el desarrollo profesional de los docentes para una educación inclusiva. En A. Marchesi, R. Blanco y L. Hernández (Ed.), Avances y desafíos de la educación inclusiva en Iberoamérica (pp. 61-70). Fundación MAPFRE.

Durán, D. y Giné, C. (2011). La formación del profesorado para la educación inclusiva: Un proceso de desarrollo profesional y de mejora de los centros para atender la diversidad. Revista Latinoamericana de Educación Inclusiva, 5(2), 153-170.

Echeita, G. y Ainscow, M. (2011). La educación inclusiva como derecho: Marco de referencia y pautas de acción para el desarrollo de una revolución pendiente. Tejuelo: Revista de Didáctica de la Lengua y la Literatura, 12, 26-46.

García, C., Herrera-Seda, C. y Vanegas, C. (2018). Competencias docentes para una pedagogía inclusiva. Consideraciones a partir de la experiencia con formadores de profesores chilenos.

Revista Latinoamericana de Educación Inclusiva, 12(2), 149-167.

https://doi.org/10.4067/S0718-73782018000200149

Gallego, C., Jiménez, A. y Corujo, C. (2018). Otra forma de desarrollar el apoyo inclusivo: Los grupos de apoyo mutuo. Revista de Investigación en Educación, 16(2), 106-120.

Hadfield, M. y Jopling, M. (2016). Problematizing lesson study and its impacts: Studying a highly contextualised approach to professional learning. Teaching and Teacher Education, 60, 203214. https://doi.org/10.1016/j.tate.2016.08.001

Hernández, F., Vöhringer, C. y Espinoza, M. (2004). Trabajo con familias en dependencia a drogas y vulnerabilidad social desde el modelo de comunidad terapéutica: Orientaciones teórico técnicas. Fundación CREDHO-CONACE.

Holmqvist, M. (2015). Learning study. Del estudio de la enseñanza al estudio del aprendizaje. El movimiento de learning study en Suecia. Revista Interuniversitaria de Formación del Profesorado, 84(3), 47-59.

Krichesky, G. J. y Murillo F. J. (2018). La colaboración docente como factor de aprendizaje y promotor de mejora. Un estudio de casos. Educación XXI, 21(1), 135-156. https://doi.org/10.5944/educxx 1.20181

Messiou, K., Ainscow, M., Echeita, G., Goldrick, S., Hope, M., Paes, I., Sandoval, M., Simón, C. y Vitorino, T. (2014). Escuchar las voces de los estudiantes y planificar juntos. Formación permanente y desarrollo profesional del profesorado. Cuadernos de Pedagogía, 446, 46-49.

Messiou, K., Ainscow, M., Echeita, G., Goldrick, S., Hope, M., Paes, I., Sandoval, M., Simon, C. y Vitorino, T. (2016). Learning from differences: A strategy for teacher development in respect to student diversity. Journal School Effectiveness and School Improvement, 27(1), 45-61. https://doi.org/10.1080/09243453.2014.966726

Molina, V. y Serrano, Z. (2016). Capítulo 31: Notas sobre la dimensión semiótico-dialógica de la docencia. En G. Padilla (Ed.), Aulas virtuales: Fórmulas y prácticas. McGraw Hill Education.

OECD. (2014). TALIS 2013 results: An international perspective on teaching and learning. OECD Publishing. https://doi.org/10.1787/9789264196261-en 
Olfos, R., Estrella, S. y Morales, S. (2015). Clase pública de un estudio de clases de estadística: Una instancia de cambio de creencias en los profesores. Revista Electrónica Educare, 19(3), 1-17. https://doi.org/10.15359/ree.19-3.21

Pérez, A. y Soto, E. (2011). Lesson study. La mejora de la práctica y la investigación docente. Cuadernos de Pedagogía, 417, 64-67.

Ramos-Rodríguez, E. y Reyes-Santander, P. (2017). Favoreciendo la reflexión del docente: Un estudio de clases sobre cálculo integral usando tecnología. Revista Electrónica Interuniversitaria de Formación del Profesorado, 20(1), 67-85. https://doi.org/10.6018/reifop/20.1.245691

Rodríguez, F. (2014). La co-enseñanza, una estrategia para el mejoramiento educativo y la inclusión. Revista Latinoamericana de Educación Inclusiva, 8(2), 219-233.

Saito, E. (2012). Strategies to promote lesson study in developing countries. International Journal of Educational Management, 26(6), 565-576. https://doi.org/10.1 108/09513541211251398

Simón, C., Echeita, G. y Sandoval, M. (2018). La incorporación de la voz del alumnado a la 'Lesson study' como estrategia de formación docente y mejora para la inclusión. Cultura y Educación, 30(1), 205-225. https://doi.org/10.1080/11356405.2017.1416741

Soto, E. y Pérez, A. I. (2015). Lesson studies: Un viaje de ida y vuelta recreando el aprendizaje comprensivo. Revista Interuniversitaria de Formación del Profesorado, 84(3), 15-28.

Pérez, Á. I., Soto, E. y Serván, M. J. (2015). Lesson studies: Re-pensar y re-crear el conocimiento práctico en cooperación. Revista Interuniversitaria de Formación del Profesorado, 84(3), 81-101.

Susinos, T., Rojas, S. y Lázaro S. (2011). La voz del alumnado y el cambio escolar en el camino hacia la inclusión educativa: Aprendiendo de la experiencia de un centro de educación infantil y primaria. Revista Latinoamericana de Educación Inclusiva, 5(2), 83-99.

Zárate-Rueda, R., Díaz-Orozco, S. y Ortíz-Guzmán, L. (2017). Educación superior inclusiva: Un reto para las prácticas pedagógicas. Revista Electrónica EDUCARE, 21(3), 1-24. https://doi.org/10.15359/ree.21-3.15

\section{Breve CV de los autores}

\section{Cynthia Duk}

Profesora de Estado en Educación Diferencial en la Universidad de Chile. Master en Integración de Personas con Discapacidad por la Universidad de Salamanca y Magíster en Docencia para la Educación Superior por la Universidad Central de Chile. Es Directora del Centro de Desarrollo e Innovación en Educación Inclusiva y del programa de Magíster en Educación Inclusiva de la Universidad Central de Chile. Además, es Directora/Editora de la Revista Latinoamericana de Educación Inclusiva que publica la Facultad de Educación en colaboración con la Red Iberoamericana de Investigación RINACE. Su línea principal de desarrollo e investigación es la educación inclusiva, la atención a la diversidad y las necesidades educativas especiales. Lideró un Proyecto de investigación y desarrollo FONDEF de Conicyt, fruto del cual se construyó el Modelo INCLUSIVA para evaluar y mejorar la respuesta de la escuela a la diversidad; así como el Estudio del Mineduc sobre "Criterios y orientaciones para flexibilizar el currículo en los distintos niveles y modalidades de enseñanza”. Tiene varias publicaciones y ha diseñado numerosos programas y materiales de apoyo a la formación y desarrollo profesional docente, entre ellos destacan el material de formación docente Educar en la Diversidad para los países 
del MERCOSUR y el Diplomado e-learning de la OEI, "Escuelas Inclusivas: enseñar y aprender en la diversidad" para los países de Iberoamérica. ORCID ID: https://orcid.org/0000-0002-8443-0707.Email: cduk@ucentral.cl

\section{Francisco Hernández-Ojeda}

Psicólogo por la Universidad de Chile. Terapeuta Familiar por el Instituto Chileno de Terapia Familiar. Coach Ontológico por Newfield Network. Magíster en Docencia para la Educación Superior por la Universidad Central de Chile. Docente del Magíster en Drogodependencias y de la Carrera Técnico en Rehabilitación en Drogas, del Programa Académico en Drogas que imparte la Facultad de Ciencias de la Salud de la Universidad Central de Chile. Dirige y gestiona proyectos de consultoría, capacitación, formación académica e intervención en salud psicológica, temáticas psicosociales y calidad de vida en empresas, instituciones educativas, del área social y del estado. Posee formación y ejerce práctica clínica de psicoterapia y terapia familiar, especializada en prevención y tratamiento del uso problemático de drogas, y en violencia infanto-adolescente grave. Entre otros textos, es coautor del libro "Trabajo con familias en dependencia a drogas y vulnerabilidad social desde el modelo de comunidad terapéutica: Orientaciones Teóricotécnicas", Fundación CREDHO y CONACE, 2004. ORCID ID: https://orcid.org/00000003-0665-7647. Email: franhero@gmail.com 